\title{
Pregnancy in a rare case of Takayasu's arteritis: a case report
}

\author{
Kushal Shah, Vaishali Korde Nayak*
}

Department of Obstetrics and Gynecology, Ruby Hall Clinic, Pune, Maharashtra, India

Received: 24 March 2019

Accepted: 14 May 2019

\section{*Correspondence:}

Dr. Vaishali Korde Nayak,

E-mail: drvaishalinayak@gmail.com

Copyright: $\odot$ the author(s), publisher and licensee Medip Academy. This is an open-access article distributed under the terms of the Creative Commons Attribution Non-Commercial License, which permits unrestricted non-commercial use, distribution, and reproduction in any medium, provided the original work is properly cited.

\begin{abstract}
In Takayasu's arteritis is a rare, chronic idiopathic vasculitis affecting aorta and its major branches, commonly seen in young women of Asian origin. Incidence is 2.6 cases/million/year. Female of reproductive age group are commonly affected. A 32-year female G3A2 with known case of Takayasu arteritis wanted to continue this pregnancy under tremandous social pressure and came for antenatal care at tertiary care hospital. As the pregnancy advanced, she developed uncontrolled hypertension and severe IUGR. At 30 weeks of gestation, elective LSCS had to be done in view of reduced fetal blood flow and severe growth restriction. She delivered male baby of $1 \mathrm{~kg}$ which was shifted to NICU. Patient required cardiac intensive care unit for first $48 \mathrm{hrs}$ and later shifted to ward. Postoperative period was uneventful, and patient could be discharged on 8th day. Baby received intensive NICU care and discharged after 1 month with $2 \mathrm{~kg}$ weight. Pregnancy with takayasu arteritis requires a multipronged management from gynaecologist, cardiologist, cardiac anaesthetist and neonatologist for favourable maternal and fetal outcome.
\end{abstract}

Keywords: Fetal growth restriction, Pregnancy, Pulseless disease, Takayasu arteritis, Uncontrolled hypertension

\section{INTRODUCTION}

Takayasu's arteritis, also known as "Pulseless Disease", is a rare, chronic, idiopathic vasculitis affecting aorta and its major branches. ${ }^{1}$ It is more common in young, reproductive age group ( $<30$ years) women of Asian origin. The incidence of Takayasu's arteritis is 2.6 cases/ million/year. ${ }^{2}$ Pathogenesis is poorly understood for Takayasu arteritis. Initial vascular lesions frequently occur in the left middle or proximal subclavian artery. With disease progression, the left common carotid, vertebral, brachiocephalic, right middle or proximal subclavian artery, right carotid, vertebral arteries, and aorta may also be affected. The abdominal aorta and pulmonary arteries are involved in approximately 50 percent of patients. The inflammation of the vessel can lead to narrowing, occlusion, or dilation of the arteries, which causes a wide range of symptoms. Initial presentation may be with low grade fever, arthralgia and myalgia with progression of symptoms leading to absent or weak peripheral pulses. Severe cases may present with limb claudication. There is difference of blood pressure in both arms of more than $10 \mathrm{mmHg}$. Almost half of the patients develop hypertension due to narrowing of the vessel wall and decreased elasticity. Patients usually have raised erythrocyte sedimentation rate and CRP which shows inflammatory activity. Imaging studies are essential to diagnose the condition and to see the extent of the disease progression. Pregnancy does not have any adverse effect on natural progression of takayasu's arteritis. But takayasu's arteritis can affect the pregnancy in many ways. Due to narrowing of the vascular channels, there is reduction in the blood supply to uterus and subsequently to fetus. Chances of complications like pre-eclampsia, eclampsia, aortic aneurysm, placental insufficiency, fetal growth restriction and sudden intrauterine death of fetus can increase many fold in pregnancy due to takayasu's arteritis. Pregnancy with takayasu can require frequent monitoring and close follow up to get the better outcome of the pregnancy. The 
objective of the present study was to comprehend the effects of takayasu's arteritis in pregnancy, complications associated with it and review available literature.

\section{CASE REPORT}

Presenting a case of 32 years old G3A2, known case of takayasu's arteritis, registered for antenatal treatment with us at 9 weeks of gestation. Her previous both abortions were medical termination of pregnancy as patient was warned against the complications and was on immunomodulator drugs like methotrexate and azathioprine.

G3-Under social and familial pressure patient planned pregnancy and was willing to continue against medical advice.

Patient was a known case of takayasu's arteritis since 2008. It was incidental finding during thyroid sonography which showed narrowing of common carotid. On further investigations, CT aortography showed 50\% stenosis of abdominal aorta. Repeat scan in 2011 showed thoracic and abdominal aorta $50 \%$ stenosed with entire left common carotid showing diffuse wall thickening. positron emission tomography computed tomography performed in 2015 and 2017 showed increased FDG activity with diffuse wall thickening in aortic arch, left common carotid, descending thoracic aorta, proximal right vertebral artery and abdominal aorta. Patient was on multiple anti-inflammatory and antihypertensive drugs before conception.

During her antenatal care at our hospital, she was started on tablet labetolol $200 \mathrm{mg} \mathrm{BD}$, tablet prednisolone $10 \mathrm{mg}$ OD, tablet ecosprin $75 \mathrm{mg}$ OD, tablet methyl dopa 500 BD after cardiologist opinion. Routine antenatal investigations were done along with antineutrophilic antibody, anti dsDNA, perinuclear antineutrophil cytoplasmic antibody and cytoplasmic antineutrophil cytoplasmic antibody, anticardiolipin ab, $\beta 2$ glycoprotein, lupus Anticoagulant which were all negative. 2D Echo was also normal. Her high sensitivity-C reactive protein erythrocyte sedimentation rate and erythrocyte sedimentation rate were raised throughout the pregnancy.

NT/NB scan was normal with double marker showing low risk. Patient was advised strict follow up biweekly with home blood pressure monitoring. Patient was also subjected to anomaly scan and routine fetal growth scan time to time. Patient was admitted at 22 weeks gestational age for complaints of breathlessness and tingling sensation in limbs and treated conservatively in joint management with cardiologist. Her Blood pressure recording in both the arms were done at every visit which showed increased blood pressure in right arm compared to left arm. The difference was more than $10 \mathrm{~mm} \mathrm{Hg}$. With increasing gestational age, the blood pressure also raised. Additional antihypertensive drugs were added. She was started on tablet labetolol $200 \mathrm{mg}$ QID, tablet amlodipine $10 \mathrm{mg}$ bd, tablet prednisolone $10 \mathrm{mg}$ od and tablet ecosprin $150 \mathrm{mg}$ OD along with 1-arginine sachet BD.

At 27 weeks growth scan, fetal growth restriction was noted which worsened rapidly as pregnancy advanced. At 28 weeks scan fetus was growing at 2nd centile and uterine artery PI was raised. As a last resort, Patient was started on Inj. clexane $40 \mathrm{mg}$ subcutaneous after due consultation with cardiologist to improve fetal blood supply. At 29 weeks, sonography showed severe fetal growth restrictions and reduced umbilical flow to fetus on doppler. Steroid doses were given.

Every alternate day dopplers were done. The day absent diastolic flow was found on Doppler, decision of termination of pregnancy was taken after counselling the patient and her relatives regarding high risk to mother and fetus with cardiac fitness. Elective lower segment caesarean section under spinal anaesthetia was done at 30 weeks of gestational age. Male baby of 1 kilogram delivered. Baby cried immediately after delivery. Baby shifted to neonatal intensive care unit immediately and intubated. Baby was given 3 doses of surfactant and kept on prolonged ventilator support.

Post operatively patient was kept in cardiac intensive care unit for $48 \mathrm{hrs}$ and later shifted to ward. Patient discharged on 8th postoperative day with multiple antihypertensive and anti-inflammatory drugs and her hospital stay was uneventful. On follow up, the wound was healthy and patient was comfortable without any complaints. Baby was discharged after 1 month of neonatal intensive care unit care with $2 \mathrm{~kg}$ weight.

\section{DISCUSSION}

The first case of takayasu's arteritis was described in 1908 by Japanese ophthalmologist Mikito Takayasu at the annual meeting of the Japan Ophthalmology Society.

He described it as a wreathlike appearance of retinal vessels with absence of radial pulse. ${ }^{3}$ In takayasu, vessel inflammation leads to wall thickening, fibrosis, stenosis, and thrombus formation. Symptoms reflect end organ ischaemia. More acute inflammation can destroy the arterial media and lead to aneurysm formation. ${ }^{4}$ In the chronic phase, the aorta is thickened secondary to fibrosis of all three vessel layers. The lumen is narrowed in a patchy distribution, often affecting multiple areas.

A etiology of Takayasu's arteritis is unknown but autoimmunity, infection \& genetics has been considered to play the role in pathogenesis of the disease. Association of Takayasu has been found with different HLA markers in different population. ${ }^{5}$ It affects mainly reproductive age group female and there are no defined guidelines for the management of pregnancy associated with Takayasu arteritis. 
There are 2 phases of the disease.

\section{Inflammatory phase}

Characterized by fever, malaise, joint pain, fatigue, fainting \& weight loss.

\section{Pulseless phase}

Vascular intimal narrowing and fibrosis causes hypertension and reduced blood flow to periphery leads to pulseless phase.

Diagnosis by angiography is gold standard. CT or MR angiogram can be used. PET scan also can be used to evaluate active disease focus. ${ }^{6}$

1990 American college of Rheumatology classification criteria for takayasu's arteritis. ${ }^{7}$

- $\quad$ Age at disease $\leq 40$ years

- Claudication of extremities

- Decreased/absent brachial artery pulse

- $\quad$ Systolic BP difference of $>10 \mathrm{~mm} \mathrm{Hg}$ between arms

- Bruit over subclavian artery or aorta

- Aortogram abnormality

Presence of any of the three or more criteria confirms the diagnosis with sensitivity $90.5 \%$ and specificity of $97.8 \%$. Another attempt of angiographic classification of takayasu's arteritis depending upon segments of aortic arch and aorta involved is given in Figure $1 .^{8}$

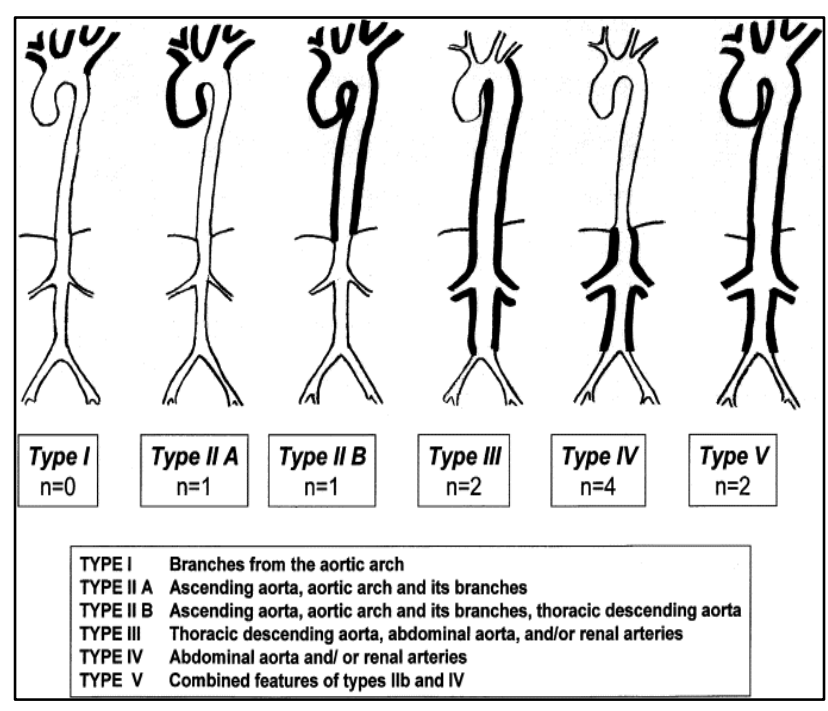

Figure 1: Angiographic classification of takayasu's arteritis.

The four most important complications for classification are retinopathy, secondary hypertension, aortic regurgitation, and aneurysm formation, each being graded as mild/moderate or severe at the time of diagnosis. Table 1 shows the ishikawa's clinical classification based on complications.

Table 1: Ishikawa's clinical classification of takayasu arteritis includes following. ${ }^{9}$

\begin{tabular}{|ll|}
\hline Group I & Uncomplicated disease, with or without pulmonary artery involvement \\
\hline Group IIA & Mild/moderate single complication together with uncomplicated disease \\
\hline Group IIB & Severe single complication together with uncomplicated disease \\
\hline Group III & Two or more complications together with uncomplicated disease \\
\hline
\end{tabular}

\section{Management during pregnancy}

Managing a case of takayasu is difficult as all the major organ systems are affected due to narrowing and fibrosis of vessels. The management requires multidisciplinary approach with team consisting of obstetrician, cardiologist, neurophysician and cardiac anaesthetist.

Maternal complications like pre-eclampsia, eclampsia, aneurysm, cardiac failure, cerebrovascular accidents and multiorgan failure due to reduced blood flow should be taken care of. Fetal complications like fetal growth restrictions, oligohydroamnios and fetal demise also should be kept in mind.

Maternal hypertension should be treated aggressively with the antihypertensives which are safe in pregnancy like labetalol, methyl dopa and nifedipine. The disease progression can be reduced with help of systemic steroids. Prednisolone can be safely given during pregnancy. Other immunomodulator drugs like methotrexate, mycophenolate mofetil are contraindicated during pregnancy so should be avoided.

Fertility is not adversely affected and pregnancy per se does not appear to exacerbate the disease, but management of hypertension is essential.

Hypertension in the second stage of labour is a risk factor for cerebral haemorrhage; shortening this stage by use of outlets forceps delivery or vacuum extraction appears to be a reasonable solution. ${ }^{10}$

Alternatively, elective lower segment caesarean section can be planned for those patients with due consideration from cardiologists and anaesthetist. 


\section{CONCLUSION}

Pregnancy in cases of takayasu's arteritis can be managed effectively with a team of expert doctors and multipronged approach for favourable maternal and fetal outcome. Long term follows up is required for those patients as the disease worsens with advancing age.

Funding: No funding sources

Conflict of interest: None declared

Ethical approval: Not require

\section{REFERENCES}

1. Lupi-Herrera E, Sánchez-Torres G, Marcushamer J. Takayasu arteritis. Clinical study of 107 cases. Am Heart J. 1977;93:94-103.

2. Hall S, Barr W, Lie JT, Stanson AW, Kazmier FJ, Hunder GG. Takayasu arteritis. A study of 32 North American patients. Medicine. 1985;64(2):89-99.

3. Takayasu M. A case with peculiar changes of the retinal central vessels. Acta Opthalmic Soc Japan. 1908;12:554-5.

4. Numano F, Okawara M, Inomata H. Takayasu's arteritis. Lancet. 2000;356:1023-5.

5. Khraishi MM, Gladman DD, Dagenais P, Fam AG, Keystone EC. HLA antigens in North American patients with Takayasu arteritis Arthritis Rheum. 1992;35(5):573-5.

6. Wen D, Du X, Ma CS. Takayasu arteritis: diagnosis, treatment and prognosis. Int Rev Immunol. 2012;31(6):462-73.

7. Krishna MV, Rudresh NS. Takayasu's arteritisStroke as an initial presentation. JIACM. 2004;5(3):274-6

8. Moriwaki R, Moda M, Yajima M. Clinical manifestations of Takayasu's arteritis in India and Japan-new classification of angiographic findings. Angiol. 1997;48:369-79.

9. Ishikawa K. Natural history and classification of occlusive thromboaortopathy (Takayasu's disease). Circulation. 1978;57:27-35.

10. Sharma BK, Jain S, Vasishta K. Outcome of pregnancy in Takayasu arteritis. Int $\mathrm{J}$ Cardiol. 2000;75:S159-62.

Cite this article as: Kushal Shah K, Nayak VK. Pregnancy in a rare case of Takayasu's arteritis: a case report. Int J Reprod Contracept Obstet Gynecol 2019;8:2563-6. 